\title{
Investigations into the coiled tubing partial underbalanced drilling (CT-PUBD) technique for drilling hard formations
}

\author{
Huai-Zhong Shi ${ }^{1,2} \cdot{\text { Zhao-Sheng } \mathrm{Ji}^{1,2} \cdot \text { He-Qian Zhao }}^{1,2} \cdot$ Heng-Yu Song ${ }^{1,2} \cdot$ Zhen-Liang Chen ${ }^{1,2}$
}

Received: 10 April 2018/Published online: 22 October 2018

(C) The Author(s) 2018

\begin{abstract}
To improve the rate of penetration (ROP) in drilling deep and hard formations, this paper proposes a new drilling method called coiled tubing partial underbalanced drilling (CT-PUBD). As a preliminary investigation into the new drilling method, this paper presents predictions of hole cleaning efficiency, drilling speed, cuttings migration and pressure loss in the drilling process with CT-PUBD. Based on numerical simulation and full-scale experimental studies, we conclude that using CT-PUBD, an underbalanced drilling condition can be achieved near the bit while maintaining wellbore safety at the same time. This condition can be achieved using a cuttings discharge device, a rotary packer and a backflow controller. According to the numerical simulations performed in this study, CT-PUBD can achieve high efficiency of hole cleaning. Along the cuttings migration process, the fluid velocities can reach the maximum values in the backflow holes. A full-scale laboratory experimental system was used to test the hydraulic characteristics and obtain the drilling performance of the new technology. The result shows that CT-PUBD significantly improves the ROP compared to the conventional drilling method.
\end{abstract}

Keywords Partial underbalanced drilling $\cdot$ Coiled tubing $\cdot$ Flow fields $\cdot$ Cuttings removal $\cdot$ Rate of penetration (ROP)

\section{Introduction}

With the increasing demand for energy, exploration and extraction of oil and gas have stepped into deep formations which normally consist of hard rocks (Chen et al. 2016a; Rui et al. 2017). In contrast to soft formations with high clay contents, hard formations cause a low rate of penetration (ROP) and a long drilling cycle, resulting in high drilling costs (Bhattacharya et al. 2013; Wang et al. 2015; Shi et al. 2015; He and Hayatdavoudi 2018). To improve ROP in hard formation drilling, special techniques such as underbalanced drilling (UBD), Reelwell drilling and coiled tubing drilling have been developed (Wang et al. 2007; Tantawy 2015; Guo et al. 2009).

Edited by Yan-Hua Sun

Huai-Zhong Shi

389805738@qq.com; shz@cup.edu.cn

1 State Key Laboratory of Petroleum Resources and Prospecting, Beijing 102249, China

2 College of Petroleum Engineering, China University of Petroleum (Beijing), Beijing 102249, China
Compared to the overbalanced drilling method, the UBD technique using low mud weight can minimize lost circulation, differential sticking and formation damage in depleted and fractured reservoirs (Salimi and Ghalambor 2011). Using the UBD technique, the bottom hole pressure can be controlled to be lower than the formation pressure. The low mud weight in UBD helps reduce rock strength and release drill cuttings from the hole bottom and subsequently increase ROP (Guo 2001). In addition to the direct use of low-density liquid (i.e., water, oil, low-density brine), the low-weight mud can also be gas (i.e., $\mathrm{N}_{2}, \mathrm{CO}_{2}$, air) or two-phase fluids such as foams and aerated liquids (Hossain and Wajheeuddin 2016; Guo et al. 2017). The main problem associated with underbalanced drilling is the poor wellbore stability (Di Meglio et al. 2014; Udegbunam et al. 2015; Cheng et al. 2013). It is also difficult to drill underbalanced in abnormal pressure formations owing to drilling safety and well control issues (Samson et al. 2015).

In 2004, the National Oil Company of Norway and Norway Science Research Council initiated an innovative drilling technique called Reelwell drilling method (RDM) (Vestavik et al. 2017; Squillace 2016; Aleksandersen and Vestavik 2015). It uses a dual-wall drill string where an 
inner pipe is used inside the traditional drill pipe. Unlike the conventional transport of drill cuttings through the borehole pipe annulus, RDM transfers drill cuttings to the surface through the inner string. The good hole cleaning effect and the accurate pressure control in the RDM promoted deepwater drilling and extended reach drilling (EDM) techniques to long horizontal well drilling (Wang and Sun 2014; Belarde and Vestavik 2011; Mirrajabi et al. 2010). However, the complicated operation procedure and the additional required tools make RDM hard to use $(\mathrm{Gu}$ et al. 2017; Belarde and Vestavik 2011; Tantawy 2015). The requirements of a high-torque capacity rig and a highflow capacity mud pump also hinder the wide application of the RDM technique (Carpenter 2017; Aleksandersen and Vestavik 2015).

Famous for its reduction in drilling cycle, coiled tubing drilling can significantly increase ROP by eliminating drill pipe connections, quick rig setup, easy wellsite maintenance, fast tripping and good well control (Livescu and Craig 2015). However, there are many problems associated with the coiled tubing drilling technique, including small hole size and low hole cleaning efficiency, especially in deviated wells (Rajmohan et al. 2012; Blanchette and Getzlaf 2015; Livescu et al. 2017a, b). Due to the inherent material properties, coiled tubing normally has a short operational life. The coiled tubing drilling technique is also difficult to use in the operations of orienting, steering and drilling long horizontal sections (Chen et al. 2016b). In addition, the daily cost in coiled tubing drilling is much more expensive than that in conventional drilling due to large number of operational personnel required on the wellsites (Livescu et al. 2017a, b).

Although all the three techniques discussed above play important roles in improving the drilling speed, there are still some problems such as poor hole cleaning, low wellbore safety and high drilling cost. To solve these problems, a new drilling technique called coiled tubing partial underbalanced drilling (CT-PUBD) is proposed here (Shi et al. 2018). It uses a dual-wall pipe system by inserting coiled tubing into the traditional drill pipe to achieve an underbalanced drilling condition near the bit. It is shown in this paper that the CT-PUBD can not only improve the drilling speed and reduce drilling time but also achieve drilling safety under underbalanced conditions.

\section{Principles of CT-PUBD}

Figure 1 shows a schematic of the CT-PUBD technique. The system consists of a drilling system, a circulation system and a monitor system. The drilling system includes such key devices as rotary packer, cuttings discharge device and backflow controller. The rotary packer is used to divide the annulus into the upper annulus and the annulus near the bit. The low-density drilling fluid is pumped into the annulus near the bit producing an underbalanced condition. The high-density drilling fluid is pumped into the upper annulus to balance the formation pressure. Through the coiled tubing and drill bit, the lowdensity drilling fluid reaches the bottom hole to cool the drill bit and clean the cuttings. Then, it flows into the micro-annulus between CT and drill string through the backflow controller to transport the cuttings to the wellhead.

The cuttings discharge device is located between the coiled tubing injector head and the Kelly. Below the Kelly, all the necessary related components are connected in sequence of drill pipe, drill collar, rotary packer, the backflow controller and drill bit. All of these components make up what is commonly referred to as a drill string. Using a coiled tubing injector head, the coiled tubing is inserted into the drill string. It is connected to the drill bit via a quick connector in the backflow controller which can also realize a fast disengagement of the coiled tubing with the drill bit. During the drilling process, the rotary packer is located outside the drill collar. It has a good setting effect and can move down with the drill bit. The backflow controller is located between the drill bit and the drill collar, in which there are holes. These holes are backflow channels for the low-density drill fluid to the micro-annulus between the drill pipe and the coiled tubing, from the bottom annulus.

Since the high-density drilling fluid is relatively stationary, the main circulation of the drilling fluid refers to the flow of the low-density drilling fluid. After being pumped into the coiled tubing, it flows into the bottom annulus through the bit nozzles. Due to the presence of the sealing rotary packer, the low-density drilling fluid flows back into the micro-annulus between the drill pipe and the coiled tubing through the backflow holes, carrying cuttings from the bottom annulus. Then, it climbs up to the wellhead and is discharged outside by the cuttings discharge device. Thus, a low-pressure zone is created near the drill bit while maintaining an overbalanced condition for the stability of the main structure of the wellbore well. As for the connection of drill pipes, the coiled tubing can be detached and reinstalled fast by a quick connector inside the backflow controller. To make the CT-PUBD technique effective and efficient, there are three-key component accessories, including a cuttings discharge device, a rotary packer and a backflow controller:

1. Cuttings discharge device (Fig. 2a): Since the main backflow channel is changed to the micro-annulus between the drill pipe and the coiled tubing, a cuttings discharge device is designed especially for the backflow of the fluid circulation of the low-density drilling 


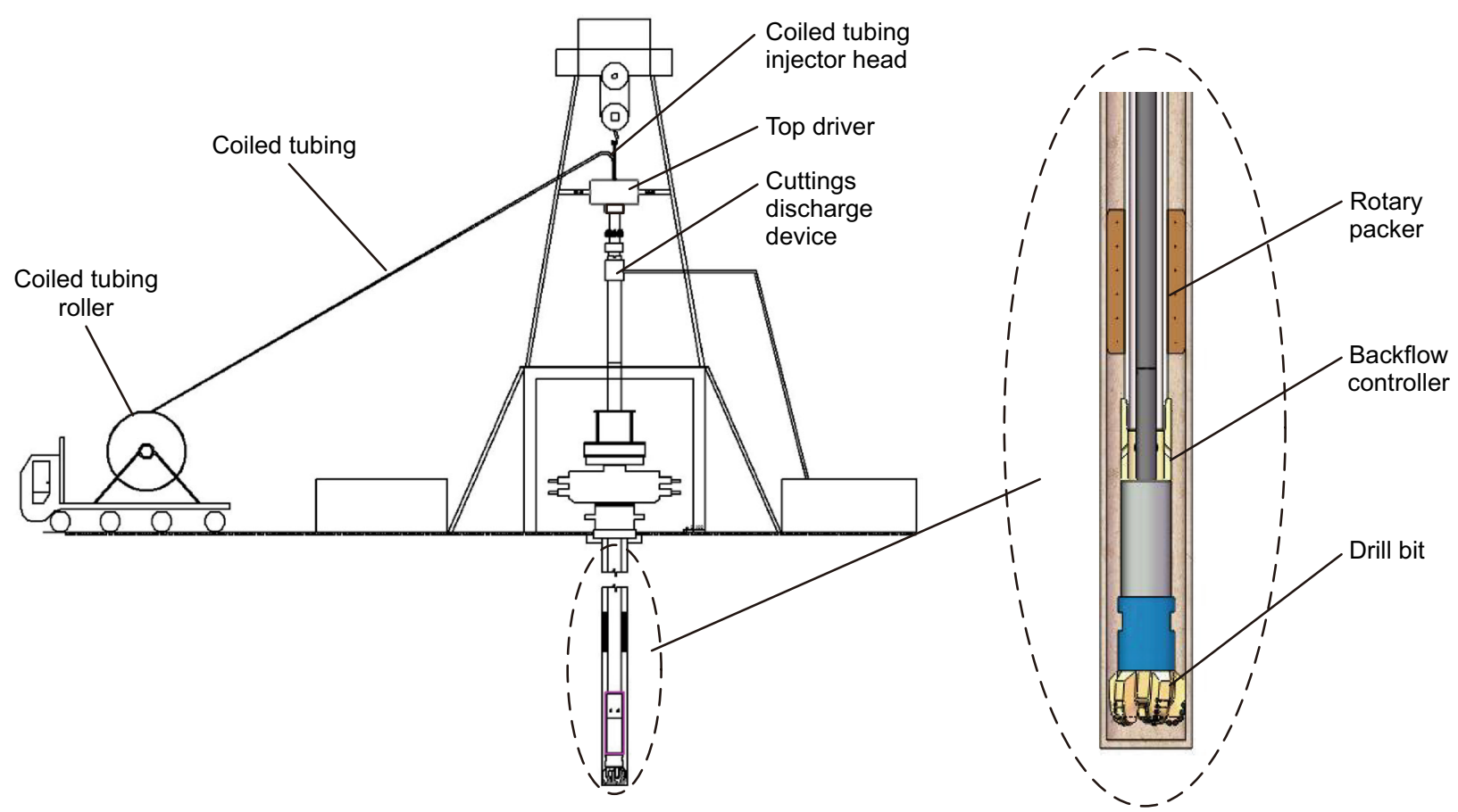

Fig. 1 Schematic of the CT-PUBD technique

(a)

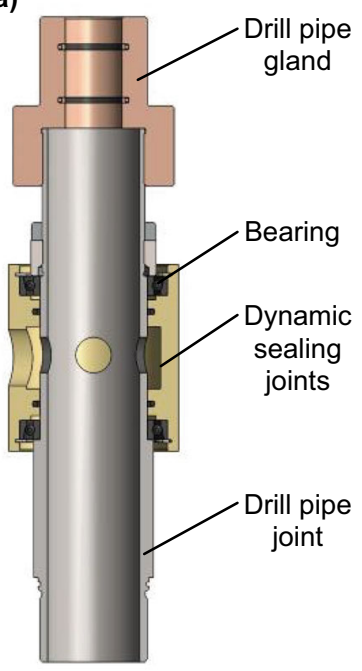

(b)

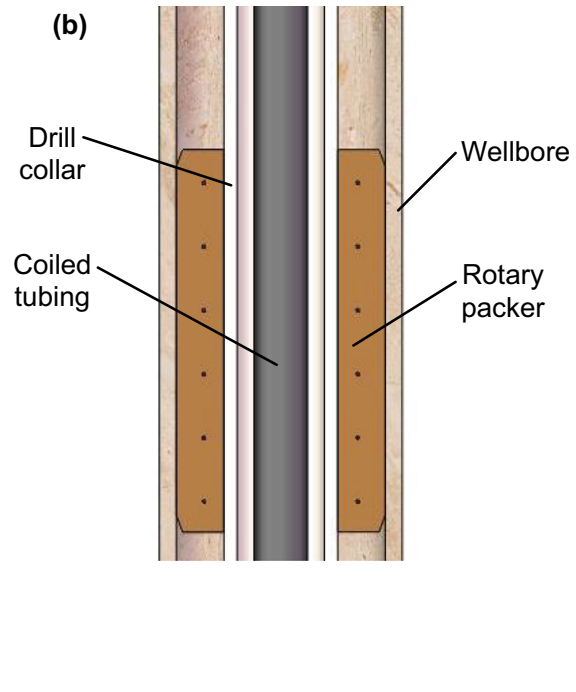

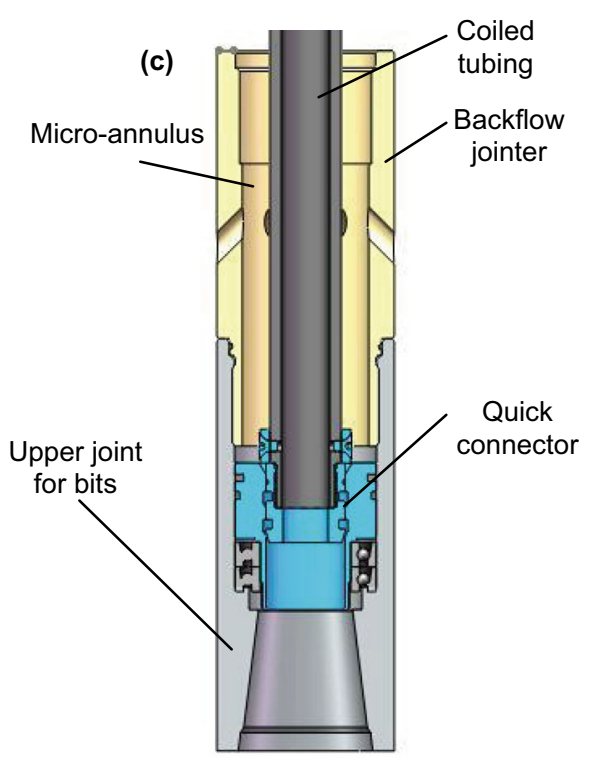

Fig. 2 Schematic diagrams. a Cuttings discharge device. b Rotary packer. c Backflow controller

mud. Surrounding the centered coiled tubing, it is located between the coiled tubing injector head and the Kelly. And it transfers the drilling mud waste (the drilling mud with cuttings) to a surface fluid-handling system. The drill pipe gland on the top of the cuttings discharge device can seal the micro-annulus effectively while the drill pipe joint is used to closely connect the drill pipes below. The dynamic sealing joints keep fixed while the drill pipe joint is rotating with the Kelly. In addition, the spatial distribution of holes in the drill pipe joint and dynamic sealing joints allows the discharge of the drill cuttings into the surface fluid-drilling system.

2. Rotary packer (Fig. 2b): The rotary packer, between the drill collar and the wellbore wall, is used to divide the normal annulus into two parts, an upper annulus and a bottom annulus near the bit. To make it possible for a low-pressure gradient near the drill bit but 
maintaining the pressure balance in the main wellbore structure, a high-density drilling fluid is pumped into the upper annulus to maintain the stability of the wellbore wall. During the drilling process, the packer can be alternately set and released to move down with the bit.

3. Backflow controller (Fig. 2c): An underbalanced drilling condition is desired near the drill bit and this can be achieved by a low-pressure-gradient drilling fluid. To achieve well-connected fluid circulation channels, a backflow controller is designed between the drill bit and the drill collar. It consists of a backflow jointer, a quick connector and an upper joint for bits. Meanwhile, holes on the backflow jointer provide flow channels of the low-density drill fluid from the bottom annulus to the micro-annulus. The quick connector can provide a quick connection and disengagement of the coiled tubing and the drill bit.

Compared with the conventional drilling technique, CTPUBD has the following features: (1) Due to the good setting effect of the rotary packer, the annulus is separated into a bottom annulus and an upper annulus. The highdensity drilling fluid in the upper annulus can ensure the drilling safety of the main wellbore structure. (2) In the bottom annulus, the hydrostatic pressure of the wellbore bottom can be controlled well. The low-density drilling fluid can create an underbalanced drilling condition, leading to an improved ROP. (3) According to the test performance, a small flow rate $(13 \mathrm{~L} / \mathrm{s})$ of drilling fluid can have a high efficiency on the bottom hole cleaning, providing guidance on releasing the cuttings deposit problem. (4) Using a lowdensity drilling fluid near the drill bit can reduce the reservoir damage (Salimi and Ghalambor 2011). Thus, it can effectively protect the productivity of the reservoir and enhance the production capacity of oil and gas wells.

\section{Numerical analysis of flow fields}

In this research, we applied the discrete phase model (DPM) to study the hydraulic characteristics of the flow fields of the annulus and the micro-annulus, i.e., the fluid velocity and the cuttings removal efficiency.

\subsection{Basic modeling of flow fields}

Using the geometric model shown in Fig. 3, we mainly studied the flow fields of the bottom annulus near the bit and the micro-annulus. As shown in the diagram, the fluid flows downward to the drill bit and into the bottom annulus. Then, it runs across the holes in the backflow controller. Finally, it flows back through the micro-annulus between the drill pipe and the coiled tubing.

The drilling parameters of the coiled tubing drilling are from elsewhere (Ozbayoglu et al. 2004), and the basic inputs are listed in Table 1. Considering the underbalanced condition, the drilling fluid density is set as $960 \mathrm{~g} / \mathrm{cm}^{3}$ which is lower than water, and the viscosity is set as $26 \mathrm{mPa}$ s (Meng et al. 2001). The mass flow rate of cuttings can be calculated from the ROP, and the formula is as follows:

$Q_{\mathrm{m}}=\frac{\mathrm{ROP} \times A}{3600} \times \rho_{\mathrm{c}}$

where $Q_{\mathrm{m}}$ is the mass flow of cuttings, ROP is the rate of penetration, $A$ is the area of bottom hole, and $\rho_{\mathrm{c}}$ is the density of the cuttings.

\subsection{Hydraulic characteristics of the bottom annulus}

In this section, the transient CFD model is used to analyze the hydraulic characteristics of the flow fields of the bottom annulus near the bit. A typical simulation capture of the flow fields is shown in Fig. 4, where the legend stands for the velocity magnitude. According to the legend scale, the warmer the color, the higher the velocity. As can be seen from the figure, the velocities of the drilling fluid and the cuttings can reach maximum values when running across the backflow holes. Meanwhile, the movement of the cuttings is more affected by the backflow holes since the overall trajectory is much shorter than that of the drilling fluid. However, the velocity distributions of both the drilling fluid and the cuttings support that the flow field can be divided into two sections:

1. Type I (active zone): This term describes the section of the bottom annulus below the backflow holes. This zone is significant for a high-velocity drilling fluid and a high efficiency of cuttings removals.

2. Type II (stagnation zone): Compared with the active zone, it refers to the zone of the bottom annulus between the rotary packer and the backflow holes. As shown in Fig. 4, we can see the decreased velocities of the drilling fluid and the cuttings when they flow through such a stagnation zone. The gradual accumulation of the drill cuttings, near the backflow holes, may have a high probability of blocking the flow channels, which must be analyzed and optimized later for a high efficiency of cuttings removals.

The backflow holes play an important role in a high efficiency of cuttings cleaning in the bottom annulus near the bit. So, a sensitivity analysis was conducted on the design parameters of backflow holes, i.e., the number $N$, 


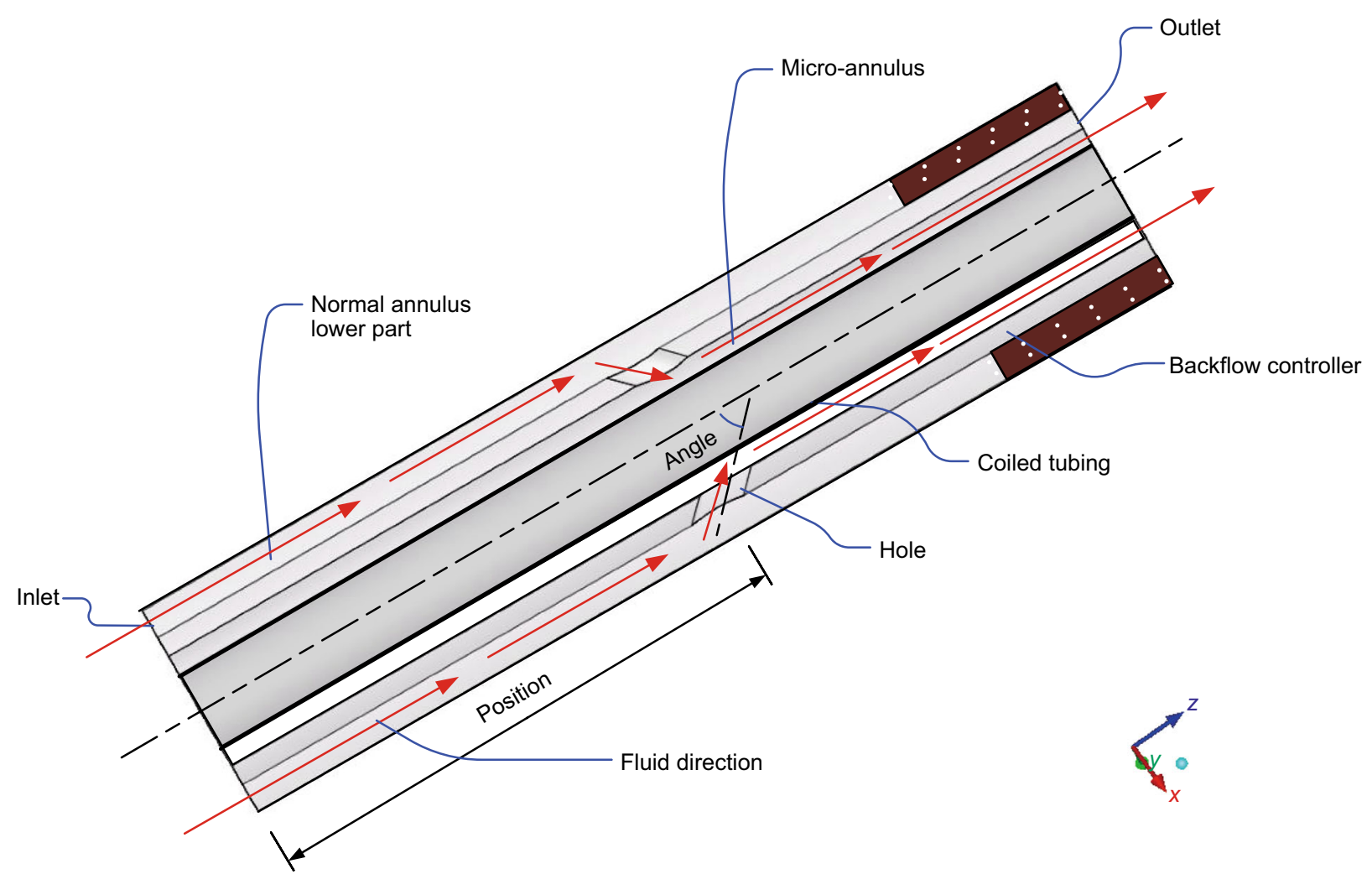

Fig. 3 Geometric model of investigated flow fields

Table 1 Basic inputs to simulation initialization

\begin{tabular}{llll}
\hline Components & Parameter & Symbol & Values \\
\hline Drilling bit & Bit diameter & $D_{\text {bit }}$ & 8 in. \\
Backflow controller & Length & $L_{\text {bf }}$ & $800 \mathrm{~mm}$ \\
& Outside diameter & $D_{\text {bfo }}$ & $178 \mathrm{~mm}$ \\
& Inside diameter & $D_{\text {bfi }}$ & $108 \mathrm{~mm}$ \\
& Holes & & \\
& Diameter & $D_{\text {bfh }}$ & $60 \mathrm{~mm}$ \\
& Number & $N$ & 3 \\
& Distance from the bit & $D$ & $500 \mathrm{~mm}$ \\
Drill pipe & Inclination angle & $\theta$ & $60^{\circ}$ \\
& Inside diameter & $D_{\text {dpi }}$ & $102.8 \mathrm{~mm}$ \\
Coiled tubing & Rotary speed & RPM & $60 \mathrm{rpm}$ \\
Low-density mud & Outside diameter & $D_{\mathrm{ct}}$ & $63 \mathrm{~mm}$ \\
& Displacement & $Q_{\mathrm{m}}$ & $18 \mathrm{~L} / \mathrm{s}$ \\
& Viscosity & $v$ & $0.026 \mathrm{~Pa} \mathrm{~s}$ \\
& Density & $\rho_{\mathrm{m}}$ & $960 \mathrm{~kg} / \mathrm{m}^{3}$ \\
Cuttings & Density & $\rho_{\mathrm{c}}$ & $2600 \mathrm{~kg} / \mathrm{m}^{3}$ \\
& Diameter & $D_{\mathrm{c}}$ & $0.004 \mathrm{~m}$ \\
& Mass flow & $Q_{\mathrm{c}}$ & $0.157 \mathrm{~kg} / \mathrm{s}$ \\
\hline
\end{tabular}

the diameter $D_{\text {bfh }}$, the distance from the bit $D$ and the inclination angle of the backflow holes $\theta$. It was carried out
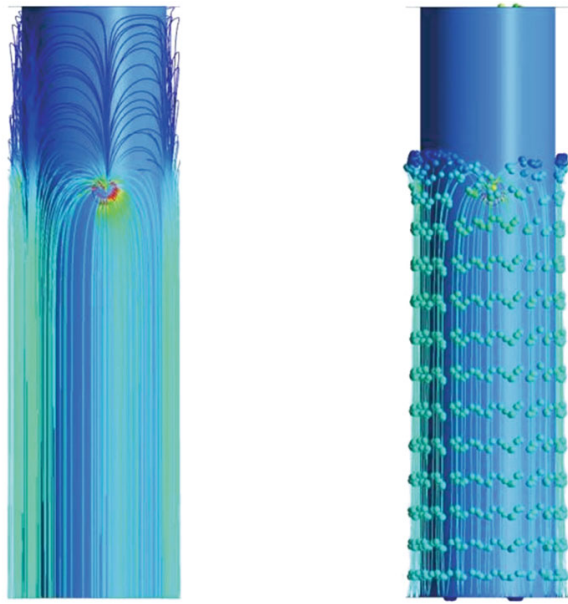

Fig. 4 Movements of drilling fluid (left) and cuttings distribution (right) in the bottom annulus $\Delta t=2 \mathrm{~s}$

with certain combinations of the parameters as shown in Table 2. The mass concentration profiles of the cuttings are shown in Fig. 5 when the flow field is stable. Then, the cuttings carrying efficiency of the drilling fluid in the bottom annulus can be evaluated along the cuttings removal direction. The mass concentration mentioned refers to the total mass of the cuttings in the annulus near the bit per $20 \mathrm{~mm}$ length of the annulus. 
Table 2 Designed parameter combinations of backflow holes

\begin{tabular}{lllll}
\hline Serial number of case & \multicolumn{5}{l}{ Parameters of backflow holes } \\
\cline { 2 - 5 } & Hole number & Hole diameter, $\mathrm{mm}$ & Hole distance, mm & Hole angle, ${ }^{\circ}$ \\
\hline (a) & $2,3,4,5$ & 30 & 500 & 60 \\
(b) & 3 & $20,30,40,50$ & 500 & 60 \\
(c) & 3 & 30 & $300,400,500,600$ & 60 \\
(d) & 3 & 30 & 500 & $30,60,90,120$
\end{tabular}
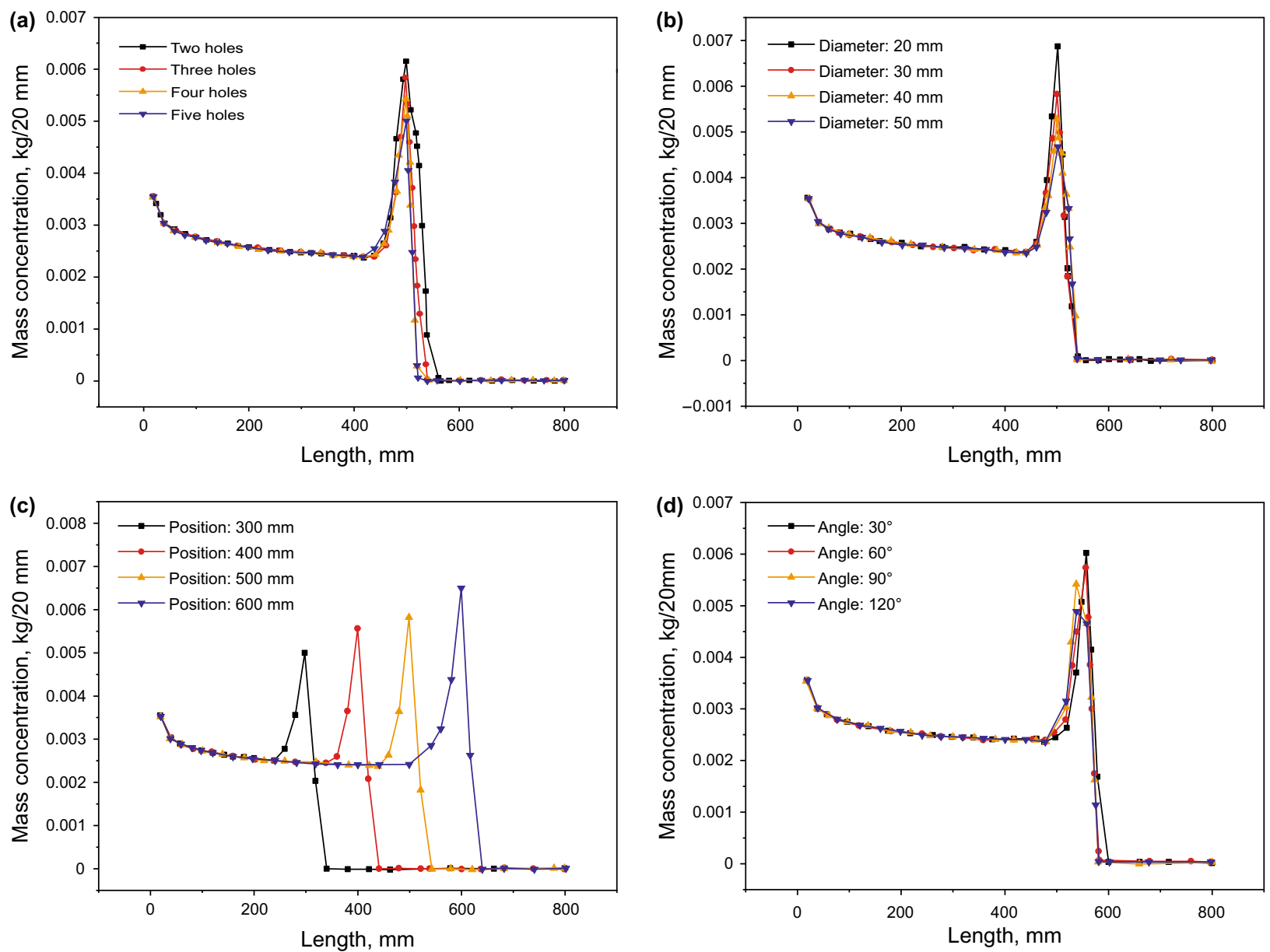

Fig. 5 Mass concentration distribution of cuttings in the annulus near the bit in conditions of different hole numbers (a), different hole diameters (b), different hole positions (c) and different hole phase angles (d)

Figure 5a shows that with the increase in the hole number $N$, the mass concentration of cuttings both in the stagnation zone and near the center of the holes decreases. But the hole number $N$ has a negligible influence on the mass concentration of cuttings below the holes. In total, the increase in the hole number $N$ is able to enhance the cuttings carrying efficiency.

Figure $5 \mathrm{~b}$ indicates that the mass concentration of cuttings near the holes decreases with the increase in the hole diameter $D_{\mathrm{bfh}}$. Therefore, the increase in the hole diameter $D_{\text {bfh }}$ is able to increase the mass of cuttings directly flowing into the holes and then to enhance the cuttings carrying efficiency.

Figure $5 \mathrm{c}$ demonstrates that as the distance of holes from the bit $D$ increases, the mass concentration of cuttings decreases in the area below the holes and increases near the holes, and the total mass of the cuttings in the area increases. Therefore, the increase in the hole position will reduce the cuttings carrying efficiency.

Figure $5 \mathrm{~d}$ illustrates that the effects of the hole phase angle $\theta$ on the mass of cuttings above and below the holes are different. The mass concentration of cuttings below the holes is almost unchanged with an increase in the hole 
angle, while the mass concentration of cuttings above the holes and near the center of the holes decreases. In total, the mass concentration of cuttings in the annulus near the bit decreases as the hole angle $\theta$ increases. Therefore, the increase in the angle is able to enhance the cuttings carrying efficiency.

A dynamic prediction on the changes of the mass of cuttings in the bottom annulus, at the conditions of case Fig. 5a, can be seen in Fig. 6. After $1.5 \mathrm{~s}$, the mass of cuttings remains relatively stable, with very small changes in the curves. In other words, the potential blocking problem can be neglected since there is no obvious increase in the mass of the cuttings inside the bottom annulus. The cuttings reach a dynamic balance between the newly generated cuttings from the wellbore hole bottom and the removal of cuttings into the micro-annulus. In other words, it has a high efficiency of hole cleaning.

\subsection{Hydraulic characteristics of the micro- annulus}

Using the CT-PUBD technique, the micro-annulus is the space between the drill pipe and the coiled tubing. Compared with the traditional annulus, the micro-annulus has distinct features. (1) Considering the sizes of the drill pipes and the coiled tubing, the micro-annulus is much smaller than the annulus between the wellbore wall and the drill strings. (2) As a traditional annulus between the wellbore wall and the drill strings, it has a rotating inside wall and a static outside wall. However, the outside wall of the microannulus, the drill strings, is rotating herein while the inside wall keeps relatively static.

The hydraulic characteristics of the drilling fluid and the drilling cuttings after they enter the micro-annulus are analyzed in this section. As shown in Fig. 7, the schematic

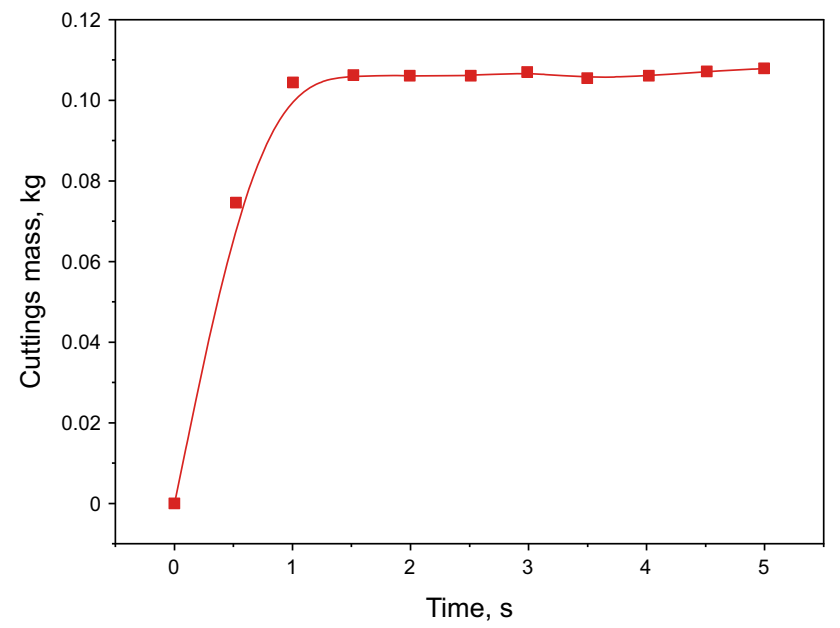

Fig. 6 A dynamic simulation of the mass of cuttings inside the bottom annulus

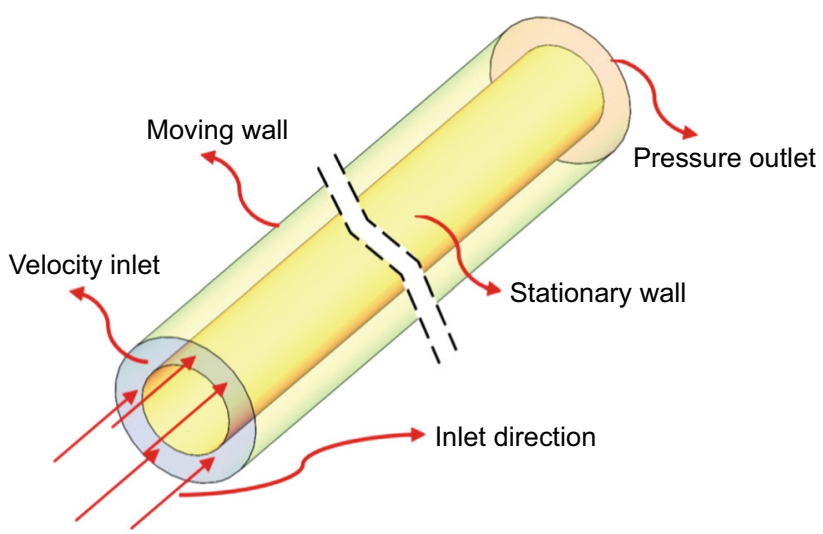

Fig. 7 Boundary condition of each section

diagram of the narrow micro-annulus is shown to clarify the boundary conditions.

Using the basic input parameters presented in Table 1, Figs. 8 and 9 show the axial velocity component and the tangential velocity component of the drilling fluid from the inside wall to the outside wall of the micro-annulus. To make the conclusion more universal, the abscissas and ordinates are normalized. The abscissas are the ratio of radius of position analyzed to that of outer wall and ordinates are the fluid velocity at the position normalized to the maximum velocity. From these figures, we can see that the axial velocity components become bigger and bigger when approaching the center of the micro-annulus, being maximum in the center and minimum near the walls. Besides, the rotation of the outside wall of the micro-annulus results in a nonlinear increase in the tangential velocity component when approaching the outside wall of the micro-annulus, being highest near the outside wall but lowest near the coiled tubing wall.

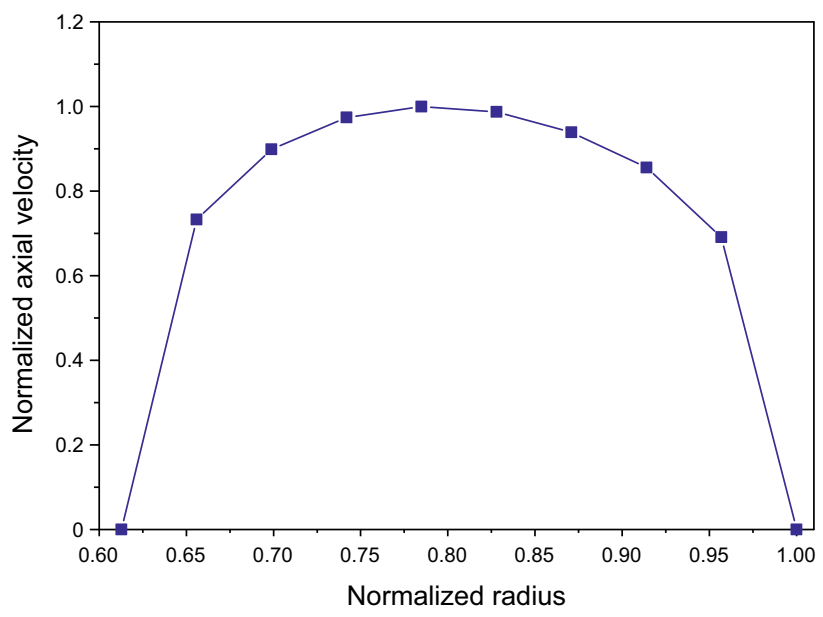

Fig. 8 Axial velocity of the drilling fluid 


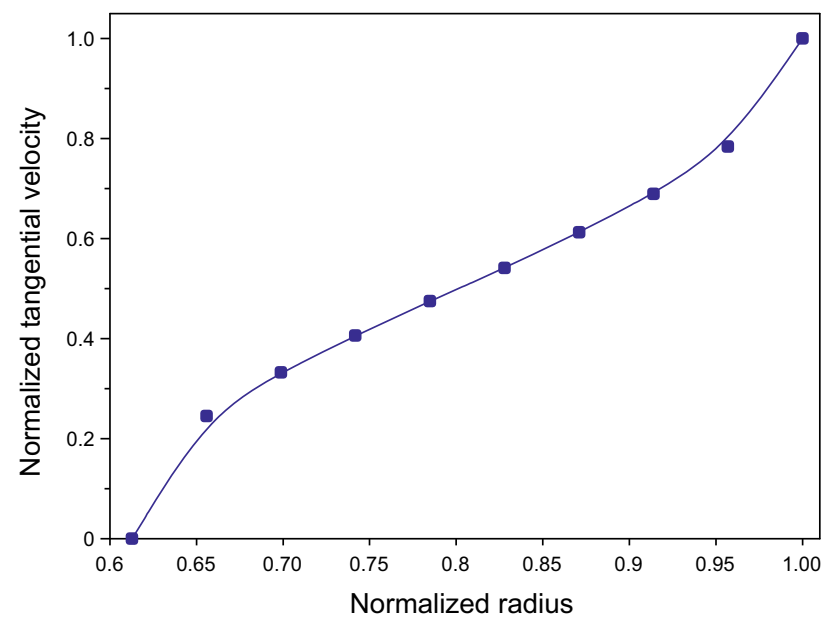

Fig. 9 Tangential velocity of the drilling fluid

\section{Experimental tests for CT-PUBD}

To study the practical drilling performance of the CTPUBD technique, a full-scale laboratory experimental system was designed and set up as shown in Fig. 10. Using the simplified experimental facilities, we can draw much useful information about the CT-PUBD technique. The hydraulic characteristics of the flow fields discussed above can be tested, using various combinations of coiled tubing, drill pipe, drilling mud and backflow controllers. With the installations of pressure sensors at desired positions, we can also collect the pressure distribution data along the circulation loop of the drilling fluid. By placing some rock samples in the wellbore bottom, the drilling performance can be evaluated, i.e., the drilling speed and the local cuttings concentration by measuring the surface cuttings. Using a specially designed drill pipe and wellbore, made of transparent Plexiglas materials, both the cuttings migration patterns in the annulus and that in the micro-annulus can be captured with a V310 high-speed photography system. By adjusting the system structure, we can also change it into a conventional drilling system, thus making it possible to compare it with the CT-PUBD technique.

Circulating a light drilling fluid with a viscosity of $1 \mathrm{mPa} s$ and a density of $1 \mathrm{~g} / \mathrm{cm}^{3}$ into the wellbore, we simulated the drilling process of CT-PUBD. As shown in Fig. 10, three pressure sensors were placed in the positions as below: Pressure sensor 1 was installed at the coiled tubing above the top driver, Pressure sensor 2 was installed near the cuttings discharge nozzles, and Pressure sensor 3 was placed at the wellhead. Thus, the differences between Pressure sensor 1 and Pressure sensor 2 describe the pressure loss of the low-density drilling fluid across the drill bit and the flow back passage. Pressure sensors 2 and 3 describe the pressure loss of the drilling fluid across the

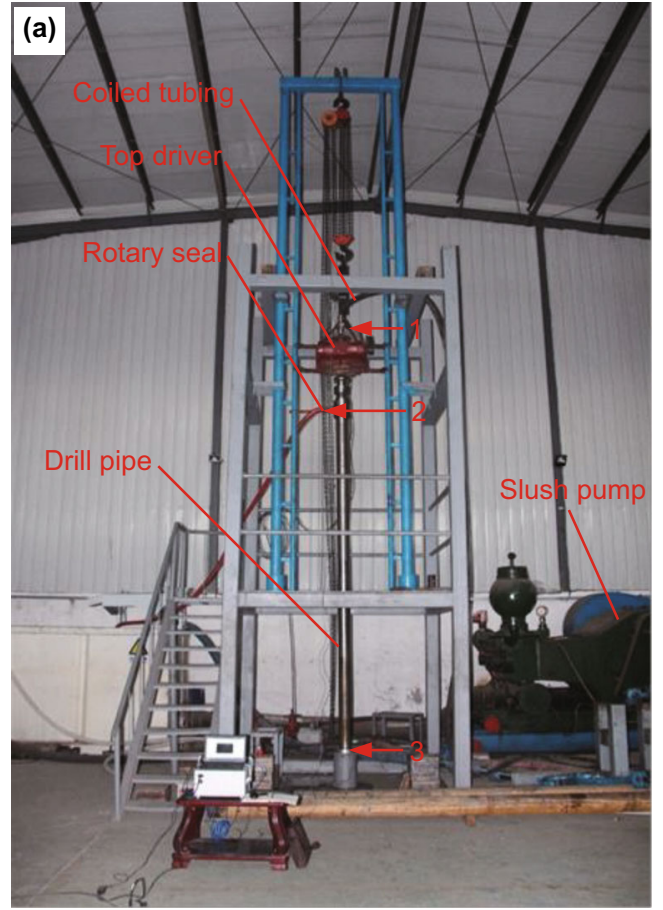

Fig. 10 A schematic diagram of full-scale indoor experimental rig. 1. Water tank; 2. inlet valve; 3 . mud pump; 4. throttle; 5 . flowmeter; 6 . pressure regulator; 7. vibrating screen; 8. experimental frame; 9. lifting hook; 10. tensimeter; 11. coiled tubing; 12. seal flange; 13. sliding girder; 14. top driver; 15. cuttings discharge device; 16.

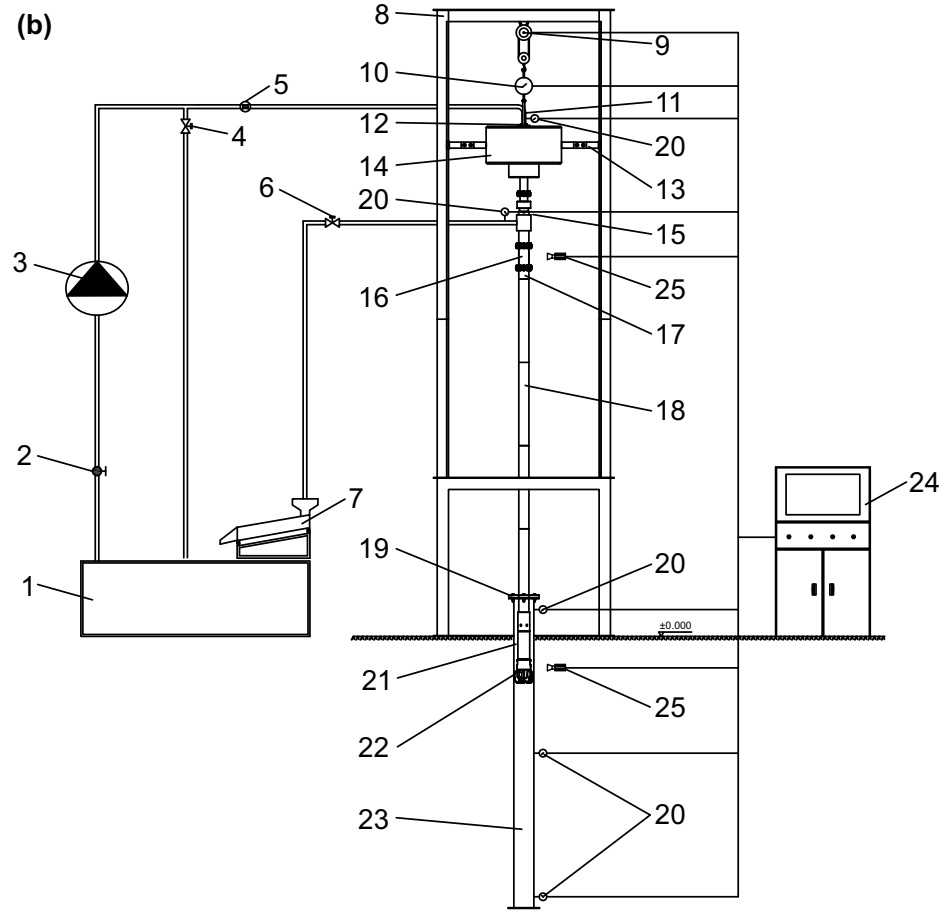

Plexiglass drill pipe; 17. adapters of drill pipe; 18. drill pipe; 19. wellbore cover; 20. pressure transformer; 21. backflow controller; 22. PDC bit; 23. designed wellbore; 24. regulation control terminal; 25. high-speed camera 
backflow passage, consisting of the backflow holes and the entire micro-annulus.

According to the pressure profile, Fig. 11a shows the readers a typical pressure record with time, where pressures started recording when the system is running stably, and the pump is stopped at the time of $2000 \mathrm{~s}$. In the conditions of laboratory experiments, the pressures are in the range between $10^{4} \mathrm{~Pa}$ and $10^{5} \mathrm{~Pa}$. Besides, the total pressure loss, between Pressure sensor 1 and Pressure sensor 2, increases linearly with an increasing flow rate of the drilling fluid as Fig. 11b, which can be used for the feasibility analyses of CT-PUBD and the optimization on key components, like the backflow designs.

We put the rock samples into the designed wellbore and conducted the CT-PUBD as well as conventional drilling. Footages of these two methods at different weight-on-bit (WOB) settings and different fluid rates were recorded in Fig. 12. It can be seen from that figure that the partial underbalanced drilling had a higher drilling speed than that of the conventional drilling at both conditions, which proved the feasibility of CT-PUBD in enhancing the ROP.

\section{Conclusions}

To improve the ROP in drilling deep and hard formations, this paper proposes a new drilling method called coiled tubing partial underbalanced drilling (CT-PUBD). As a preliminary investigation into the new drilling method, this paper presents predictions of hole cleaning efficiency, drilling speed, cuttings migration and pressure loss in the drilling process with CT-PUBD. Based on numerical simulation and full-scale experimental studies, the following key conclusions are drawn:

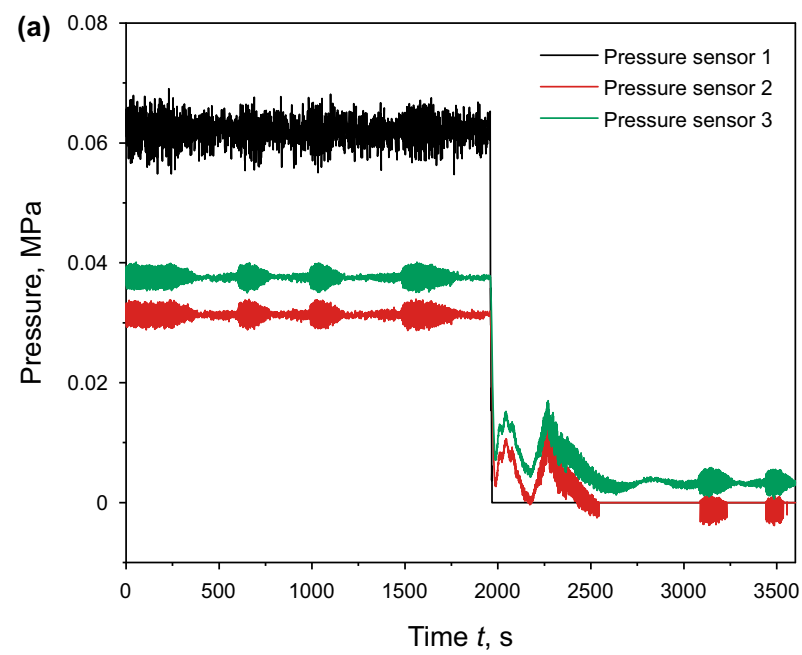

1. Using CT-PUBD, an underbalanced drilling condition can be achieved near the bit while maintaining wellbore safety at the same time. This condition can be achieved using a cuttings discharge device, a rotary packer and a backflow controller.

2. According to the numerical simulations performed in this study, CT-PUBD can achieve high efficiency of hole cleaning. Along the cuttings migration path, the fluid velocities reach the maximum values in the backflow holes.

3. A full-scale indoor experimental system was used to test the hydraulic characteristics and obtain the drilling performance of the new technology. The result shows that CT-PUBD significantly improved the ROP when compared to the conventional drilling method.

\section{Discussion}

Although having many advantages, CT-PUBD may also have some challenges when applied in the field. For example, this method has high requirements for the reliability of downhole supporting equipment, i.e., the rotary packer and the multifunctional connector; there is a certain risk of the wellhead blowout preventer (BOP) controlling the micro-annulus pressure when a connection is made; and lowering and lifting operations for coiled tubing working machine need to be fast and safe. Therefore, the technical processes supporting this method need further improvement. The use of coiled tubing shows that the method is more suitable for shallow formations. When optimizing the hole diameter and the hole number, it is not only necessary to consider the cuttings carrying efficiency, but also to consider whether the strength of the backflow device can

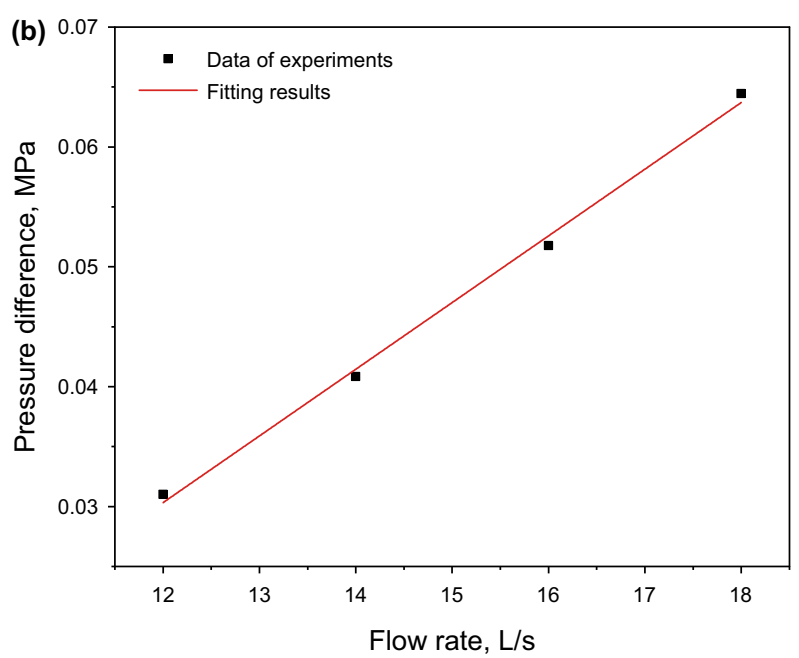

Fig. 11 Pressure profiles with the increasing time (a) and the fluid rate (b) 

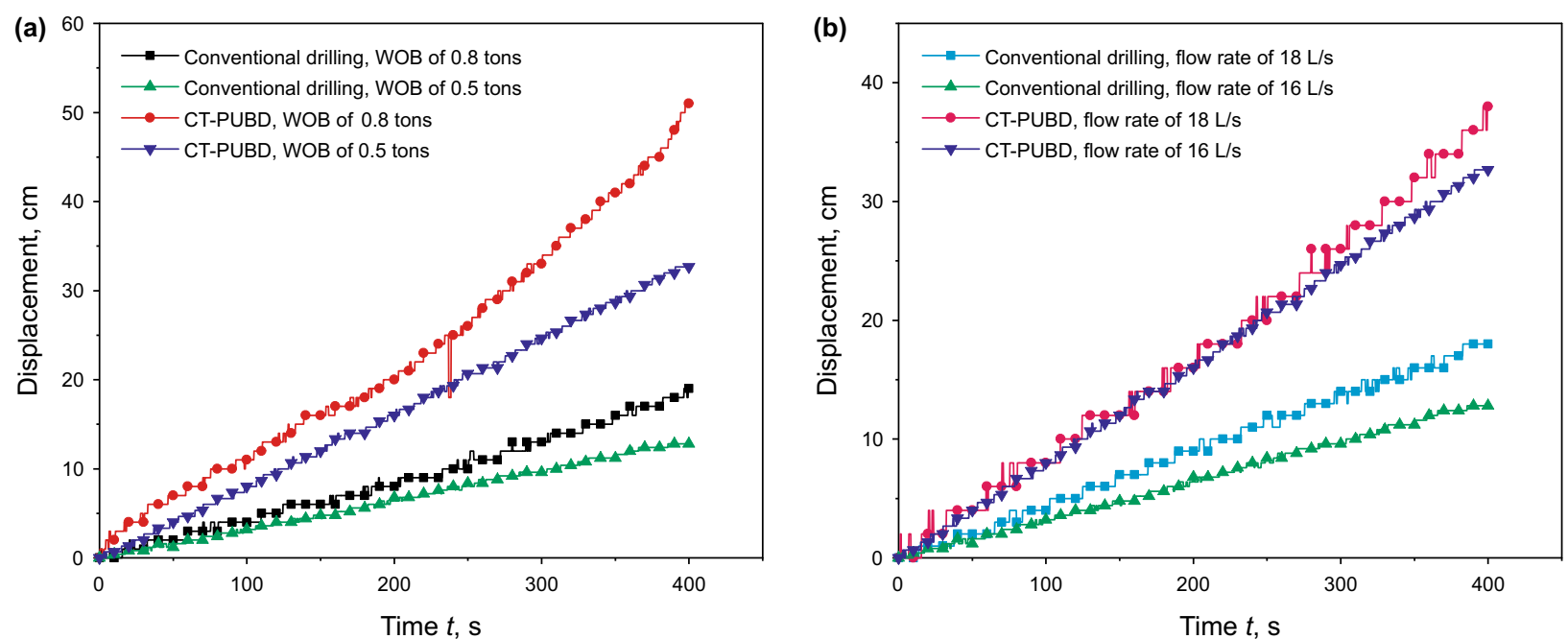

Fig. 12 Drilling performances of CT-PUBD and conventional drilling at different WOB, fluid flow rate of $16 \mathrm{~L} / \mathrm{s}$, rotary speed of $80 \mathrm{rpm}(\mathbf{a})$ and different flow rates of drilling fluids, WOB of 0.5 tons, rotary speed of $80 \mathrm{rpm}(\mathbf{b})$

meet the requirements, which requires further work to verify. In addition, in the choice of hole diameter it also takes into account the cuttings size to prevent clogging of the holes of backflow device. In general, this method may be not mature enough and needs further research and improvement.

Acknowledgements The authors acknowledge the National Natural Science Foundation of China (Grant No. 51474232). The support from the National Science and Technology Major Project (Grant No. 2016ZX05022) for this research is very much appreciated.

Open Access This article is distributed under the terms of the Creative Commons Attribution 4.0 International License (http://creative commons.org/licenses/by/4.0/), which permits unrestricted use, distribution, and reproduction in any medium, provided you give appropriate credit to the original author(s) and the source, provide a link to the Creative Commons license, and indicate if changes were made.

\section{References}

Aleksandersen J, Vestavik OM. Dual-drillpipe method shows success in PMCD wells with cuttings return. J Pet Sci Technol. 2015;67(04):32-5. https://doi.org/10.2118/0415-0032-JPT.

Blanchette C, Getzlaf D. New downhole data clarifies coiled tubing behavior in horizontal wells. In: SPE/CSUR unconventional resources conference, 20-22 October, Calgary, Alberta, Canada; 2015. https://doi.org/10.2118/175974-MS.

Belarde MA, Vestavik OM. Deployment of Reelwell drilling method in shale gas field in Canada. In: Offshore Europe, 6-8 September, Aberdeen, UK; 2011. https://doi.org/10.2118/ 145599-MS.

Bhattacharya K, Javed A, Khanna AK, Shrivastava S, Pratap KK. Realizing enhanced drilling efficiency by implementing air hammer technology in extremely hard and abrasive rock formations. In: SPE/IADC Middle East drilling technology conference and exhibition, October, 2013. https://doi.org/10. 2118/166726-MS
Carpenter C. Horizontal drilling with dual-channel drillpipe. J Pet Sci Technol. 2017;69(11):53-5. https://doi.org/10.2118/1117-0053JPT.

Chen X, Gao D, Guo B, Feng Y. Real-time optimization of drilling parameters based on mechanical specific energy for rotating drilling with positive displacement motor in the hard formation. J Nat Gas Sci Eng. 2016a;35:686-94. https://doi.org/10.1016/j. jngse.2016.09.019.

Chen Y, Zhang S, Wang W, Xiong M. Experimental study on axial load transfer behavior of a coiled tubing stuck in a marine riser. Proc Inst Mech Eng M J Eng. 2016b;230(2):241-9. https://doi. org/10.1177/1475090214563858.

Cheng YF, Li LD, Mahmood S, Cui Q. Fluid-solid coupling model for studying wellbore instability in drilling of gas hydrate bearing sediments. Appl Math Mech Engl. 2013;34(11):1421-32. https:// doi.org/10.1007/s10483-013-1756-7.

Di Meglio F, Bresch-Pietri D, Aarsnes UJF. An adaptive observer for hyperbolic systems with application to underbalanced drilling. IFAC Proc Vol. 2014;47(3):11391-7.

Gu J, Wang S, Ma C, Gan P, Tang N. Influence of drilling fluid components on shear strength at cement-aquifuge interface in coalbed methane wells. Acta Geol Sin-Engl. 2017;91(4):1511-2. https://doi.org/10.1111/1755-6724.13386.

Guo B. Use of spreadsheet and analytical models to simulate solid, water, oil and gas flow in underbalanced drilling. In: SPE/IADC Middle East drilling technology conference, 22-24 October, Bahrain, 2001. https://doi.org/10.2118/72328-MS.

Guo B, Li J, Song J, Li G. Mathematical modeling of heat transfer in counter-current multiphase flow found in gas-drilling systems with formation fluid influx. Pet Sci. 2017;14(4):711-9. https:// doi.org/10.1007/s12182-017-0164-3.

Guo R, Li G, Huang Z, Tian S, Zhang X, Wu W. Theoretical and experimental study of the pulling force of jet bits in radial drilling technology. Pet Sci. 2009;6(4):395-9. https://doi.org/10. 1007/s12182-009-0060-6.

He W, Hayatdavoudi A. A comprehensive analysis of fracture initiation and propagation in sandstones based on micro-level observation and digital imaging correlation. J Pet Sci Eng. 2018;164:75-86. https://doi.org/10.1016/j.petrol.2018.01.041.

Hossain ME, Wajheeuddin M. The use of grass as an environmentally friendly additive in water-based drilling fluids. Pet Sci. 
2016;13(2):292-303. https://doi.org/10.1007/s12182-016-00838.

Livescu S, Craig S. Increasing lubricity of downhole fluids for coiledtubing operations. SPE J. 2015;20(02):396-404. https://doi.org/ 10.2118/168298-MS.

Livescu S, Watkins T, Najafov J. 10 years of continuous technology development and field application of a coiled tubing telemetry system: past, present and future. In: SPE annual technical conference and exhibition, 9-11 October, San Antonio, Texas, USA, 2017a. https://doi.org/10.2118/187374-MS.

Livescu S, Craig S, Aitken B. Fluid-hammer effects on coiled-tubing friction in extended-reach wells. SPE J. 2017;22(01):365-73. https://doi.org/10.2118/179100-PA.

Meng QS, Zhao XQ, Guo CX. Drilling fluid technology for underbalanced drilling in the Tahe Oilfield. Drill Fluid Complet Fluid. 2001;18(2):30-2. https://doi.org/10.3969/j.issn.10015620.2001.02.009 (in Chinese).

Mirrajabi M, Nergaard AI, Hole O, Vestavik OM. Riserless reelwell drilling method to address many deepwater drilling challenges. In: IADC/SPE drilling conference and exhibition, 2-4 February, New Orleans, Louisiana, USA, 2010. https://doi.org/10.2118/ 126148-MS.

Ozbayoglu ME, Miska SZ, Reed T, Takach N. Analysis of the effects of major drilling parameters on cuttings transport efficiency for high-angle wells in coiled tubing drilling operations. In: SPE/ICo TA coiled tubing conference and exhibition, 23-24 March, Houston, Texas; 2004. https://doi.org/10.2118/89334-MS.

Rajmohan T, Palanikumar K, Davim JP. Analysis of surface integrity in drilling metal matrix and hybrid metal matrix composites. J Mater Sci Technol. 2012;28(8):761-8. https://doi.org/10.1016/ S1005-0302(12)60127-3.

Rui Z, Lu J, Zhang Z, Guo R, Ling K, Zhang R, Patil S. A quantitative oil and gas reservoir evaluation system for development. J Nat Gas Sci Eng. 2017;42:31-9. https://doi.org/10.1016/j.jngse.2017. 02.026 .

Salimi S, Ghalambor A. Experimental study of formation damage during underbalanced-drilling in naturally fractured formations. Energies. 2011;4:1728-47. https://doi.org/10.3390/en4101728.
Samson FA, Gbadegesin A, Kelani B, Olalekan O. Improved model for predicting annulus pressure drop during underbalanced drilling. J Pet Environ Biotechnol. 2015;6(203):2. https://doi. org/10.4172/2157-7463.1000203.

Shi H, Li G, Huang Z, Li J, Zhang Y. Study and application of a highpressure water jet multi-functional flow test system. Rev Sci Instrum. 2015;86:125111. https://doi.org/10.1063/1.4938162.

Shi HZ, Ji ZS, Zhao HQ, Chen ZL, Zhang HZ. An experimental system for coiled tubing partial underbalanced drilling (CTPUBD) technique. Rev Sci Instrum. 2018;89:55108. https://doi. org/10.1063/1.5029303.

Squillace M. Managing unconventional oil and gas development as if communities mattered. Vermont Law Review. 2016;40:525-60.

Tantawy HF. The application of the Reelwell drilling method in drilling and casing a vertical well in one-hole section. In: SPE Bergen one day seminar, 22 April, Bergen, 2015. https://doi.org/ 10.2118/173866-MS.

Udegbunam JE, Fjelde KK, Evje S, Nygaard G. On the advectionupstream-splitting-method hybrid scheme: a simple transientflow model for managed-pressure-drilling and underbalanceddrilling applications. SPE Drill Complet. 2015;30(02):98-109. https://doi.org/10.2118/168960-PA.

Vestavik OM, Thorogood J, Bourdelet E, Schmalhorst B, Roed JP. Horizontal drilling with dual channel drill pipe. In: SPE/IADC drilling conference and exhibition, 14-16 March, The Hague, The Netherlands, 2017. https://doi.org/10.2118/184683-MS.

Wang X, Zhang L, Chao G. The heterogeneity of lacustrine shale gas reservoir in Yanchang formation, Xiasiwan area. Ordos Basin. Acta Geol Sin-Engl. 2015;89(s1):99-101. https://doi.org/10. 13745/j.esf.2016.01.012.

Wang Z, Sun Q. Corotational nonlinear analyses of laminated shell structures using a 4-node quadrilateral flat shell element with drilling stiffness. Acta Metall Sin. 2014;30(3):418-29. https:// doi.org/10.1007/s10409-014-0009-x.

Wang ZM, Ping LQ, Zou K. Prediction of dynamic wellbore pressure in gasified fluid drilling. Pet Sci. 2007;4(4):66-73. https://doi. org/10.1007/BF03187458. 